\title{
Right Atrium Myxoma in an 11-Year-Old Girl in Guinea
}

\author{
Barry Ibrahima Sory', Balde El Hadj Yaya1, Camara Abdoulaye ${ }^{*}{ }^{\circledR}$, Koivogui Kokoulo1, \\ Samoura Aly¹, Koivogui Diarra', Soumaoro Morlaye1, Toure Demba², Camara Aboubacar², \\ Bah Mamadou Bassirou1, Sylla Fatou², Beavogui Mariame1, Balde Mamadou Dadhi', \\ Conde Mamady ${ }^{1}$
}

\author{
${ }^{1}$ Department of Cardiology at Ignace Deen National Hospital CHU, Conakry, Republic of Guinea \\ ${ }^{2}$ Pneumology department of the Ignace Deen National Hospital CHU, Conakry, Republic of Guinea \\ Email: *mariboudou@gmail.com
}

How to cite this paper: Sory, B.I., El Hadj Yaya, B., Abdoulaye, C., Kokoulo, K., Aly, S., Diarra, K., Morlaye, S., Demba, T., Aboubacar, C., Bassirou, B.M., Fatou, S., Mariame, B., Dadhi, B.M. and Mamady, C. (2020) Right Atrium Myxoma in an 11-Year-Old Girl in Guinea. World Journal of Cardiovascular Diseases, 10, 432-436.

https://doi.org/10.4236/wjcd.2020.107042

Received: February 26, 2020

Accepted: July 11, 2020

Published: July 14, 2020

Copyright $\odot 2020$ by author(s) and Scientific Research Publishing Inc. This work is licensed under the Creative Commons Attribution International License (CC BY 4.0).

http://creativecommons.org/licenses/by/4.0/

\begin{abstract}
The objective of this study was to describe the myxoma of the right atrium occurring in an 11-year-old girl. It was an 11-year-old girl weighing $22 \mathrm{~kg}$, admitted for exertional dyspnea, dry cough, palpitations, hepatitis, abdominal bloating, fever evolving for more than 9 months without a history of known cardiovascular disease; referral from a pulmonology department for cardiomegaly and right pleurisy. At cardiac auscultation, the rhythm was irregularly fast at 130 beats without added noise with a blood pressure of 110/65 mmhg. In the lungs, there was silence and a decrease in vocal vibrations at the right base, $\mathrm{SaO}_{2}$ at $70 \%$. Elsewhere a thoracic collateral venous circulation was visible. Electrocardiogram recorded rapid atrial fibrillation at 134 cycles. The cardiac ultrasound concluded that there was a mobile mass in the right atrium prolapsing in the right ventricle measuring $25 \mathrm{~mm} \times 18.9 \mathrm{~mm}$ suggesting a myxoma. The myxoma of the right atrium is of a rare localization with a polymorphic clinical manifestation. It should be diagnosed as early as possible to avoid the occurrence of dreaded complications. Its management is surgical.
\end{abstract}

\section{Keywords}

Myxoma, Right Atrium, 11-Year-Old Girl, Guinea

\section{Introduction}

About $80 \%$ of primary cardiac tumors are benign, more than half of which are myxomas [1]. The atrium myxoma is a rare benign tumor. Its location in the right atrium is unusual and is found in $15 \%$ to $20 \%$ of cases of cardiac myxoma 
[2]. This form can be complicated by pulmonary embolism and right heart failure and it is characterized by a clinical picture often misleading [3] [4] [5]. The objective of this study was to describe the myxoma of the right atrium occurring in an 11-year-old girl.

\section{Observation}

It was an 11-year-old girl weighing $22 \mathrm{~kg}$, admitted for exertional dyspnea, dry cough, palpitations, hepatitis, abdominal bloating, fever developing for more than 9 months. Without a history of known cardiovascular disease; referral from a pulmonology department for cardiomegaly and right pleurisy, at cardiac auscultation, the rhythm was irregular fast at 130 beats without added noise with a blood preasure at 110/65 mmhg. In the lungs, there was silence and a decrease in vocal vibrations at the right base, $\mathrm{SaO}_{2}$ at $70 \%$. Elsewhere a thoracic collateral venous circulation was visible. Electrocardiogram recorded rapid atrial fibrillation at 134 cycles. The cardiac ultrasound concluded that there was a mobile mass in the prolapsing right atrium in the right ventricle measuring $25 \mathrm{~mm} \times$ $18.9 \mathrm{~mm}$ suggesting a myxoma (Figure 1). The abdominal ultrasound showed an aspect in favor of the cardiac liver with a hepatic arrow at $13.5 \mathrm{~cm}$ and dilation of the inferior vena cava. The chest $\mathrm{x}$-ray showed an overflow from the right lower arch, cardiomegaly with a cardiothoracic index of 0.57 , and filling of the right diaphragmatic costo sac sac. Biology revealed anemia of $10 \mathrm{~g} / \mathrm{dl}$; a leukocytosis at 28 giga/l; a hyper lymphocytosis at 13.5 giga/l, the retroviral serology was negative. The rest of the exam was unremarkable.

At the end of the clinical and para-clinical examination, the diagnosis of myxoma of the right atrium was retained. The girl had benefited from treatment with anti aldosterone, a beta blocker and oxygen therapy. The excision of the myxoma was

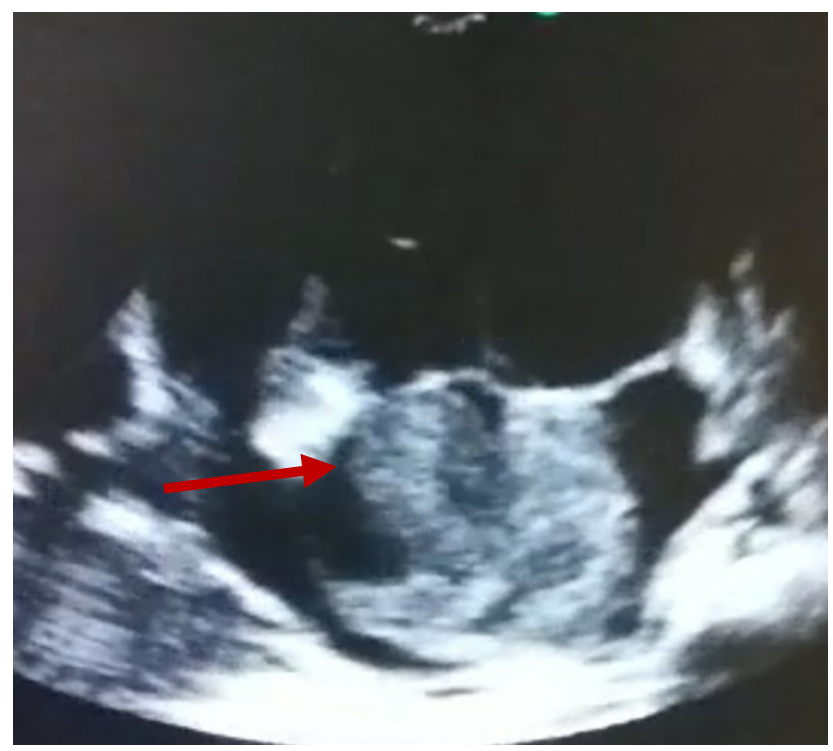

Figure 1. Cardiac ultrasound showing a mobile mass in the right atrium prolapsing in the right ventricle measuring $25 \mathrm{~mm} \times 18.9 \mathrm{~mm}$ evoking a myxoma. 
not done for lack of technical platform for cardiac surgery. The evolution was marked by the patient's death the day after her admission. The evolution was marked by the death of the patient.

\section{Discussion}

We report the case of a right atrium myxoma in an 11-year-old girl in Guinea.

Myxoma can occur at any age, but more commonly between 30 and 60 years of age [6]. A predominance of women has been reported by most studies [6] [7]. Our subject was female and only 11 years old, unlike that reported by Noureddine Atmani in Rabat who was 60 years old and male. [8] Clinically, cardiac myxomas are generally revealed by one of the elements of the classic triad: general nonspecific signs, peripheral embolism or a valve obstruction or cardiac chambers [9]. This patient was admitted for dyspnea, hepatitis, abdominal bloating related to ascites and a fever. Right atrium myxomas frequently have a polymorphic and non-specific clinical picture [3] [10], which is often a source of diagnostic delay. In a study of symptomatic patients with atrial myxoma, the average time between onset of symptoms and diagnosis is 10.6 months. Thus approximately $15 \%$ of cardiac myxomas are discovered fortuitously [11]. The onset of symptoms and the diagnosis of myxoma were approximately 9 months. Trans thoracic ultrasound is the benchmark examination for diagnosis, it allows the diagnosis of the tumor and the study of different cardiac structures [3]. This is the case of our patient in whom Cardiac ultrasound concluded the presence of a mobile mass in the right atrium prolapsing in the right ventricle measuring $25 \mathrm{~mm} \times$ $18.9 \mathrm{~mm}$ evoking a myxoma (Figure 1). ETO is more sensitive for the detection of myxomas, especially when they are small. However, it can be dangerous, Cavero et al. [12] reported a case of sudden death from massive pulmonary embolism during TEE. The treatment of cardiac myxomas is surgical. The principles of this treatment have been listed by Jones [13]: minimal manipulation of the heart and tumor; adequate exposure allowing the entire tumor to be removed; inspection of the four heart chambers; the reduction of recurrences; be safe and effective. Our patient did not benefit from surgical excision of this tumor due to lack of technical platform. Indeed, the absence of cardiac surgery in our country is a real problem for the management of diseases requiring this surgery. The results of the myxoma excision are satisfactory with a mortality close to $1 \%$. In the long term there is a low risk of recurrence that Shinfeld et al. [14] estimate from $1 \%$ to $5 \%$. The evolution of our patient was fatal marked by death the day after the diagnosis of this myxoma either by pulmonary embolization or obstruction of the tricuspid valve.

\section{Conclusion}

The myxoma of the right atrium is of a rare localization with a polymorphic clinical manifestation. It should be diagnosed as early as possible to avoid the occurrence of dreaded complications. Its management is surgical. 


\section{Author Contribution}

All authors have contributed to the improvement of this manuscript.

\section{Conflicts of Interest}

The authors declare no conflicts of interest regarding the publication of this paper.

\section{References}

[1] Castillo, J.G. and Silvay, G. (2010) Characterization and Management of Cardiac Tumors. Seminars in Cardiothoracic and Vascular Anesthesia, 14, 6-20. https://doi.org/10.1177/1089253210362596

[2] Reynen, K. (1995) Medical Progress: Cardiac Myxomas. The New England Journal of Medicine, 333, 1610-1617. https://doi.org/10.1056/NEJM199512143332407

[3] Mbaye, A., Yameogo, N.V., Kane, A.D., et al. (2010) Large Myxoma of the Right Atrium Revealed by Right Heart Failure. Annales de Cardiologie et d Angéiologie, 59, 40-43. https://doi.org/10.1016/j.ancard.2009.07.004

[4] Canale, L.S., Siciliano, C.A., Botelho, E.S.L. and Monteiro, A.J. (2009) Treatment of Right Atrialmyxoma Complicated with Pulmonary Embolism. Interactive CardioVascular and Thoracic Surgery, 9, 535-536. https://doi.org/10.1510/icvts.2009.206318

[5] Garatti, A., Nano, G., Canziani, A., Gagliardotto, P., Mossuto, E., Frigiola, A., et al. (2012) Surgical Excision of Cardiac Myxomas: Twenty Years Experience at a Single Institution. The Annals of Thoracic Surgery, 93, 825-831. https://doi.org/10.1016/j.athoracsur.2011.11.009

[6] Denguir, R., Dhiab, M., Meddeb, I., Hermi, N., Khanfir, I., Ben Romdhane, R., et al. (2006) Cardiac Myxomas. Surgical Management. About 20 Cases. Annales de Cardiologie et d Angéiologie, 55, 49-54. https://doi.org/10.1016/j.ancard.2005.04.011

[7] Dong Hi, A.Y. and Williams, C.R. (2002) Sex Distribution in Cardiac Myxomas. American Journal of Cardiology, 90, 563-565. https://doi.org/10.1016/S0002-9149(02)02540-7

[8] Atmani, N., Nya, F., Moutakiallah, Y., Abdou, A., Bamous, M., Houssa, M.A. and Boulahya, A. (2013) Myxoma of the Right Atrium Complicated by Pulmonary Embolism and Revealed by Right Heart Failure. Elsevier Masson SAS, Amsterdam.

[9] Nina, V.J., Silva, N.A., Gaspar, S.F., Rapôso, T.L., Ferreira, E.C., Nina, R.V., et al. (2012) Atypical Size and Location of a Right Atrial Myxoma: A Case Report. Journal of Medical Case Reports, 6, 26. https://doi.org/10.1186/1752-1947-6-26

[10] Mahilmaran, A., Seshadri, M., Nayar, P.G., Sudarsana, G. and Abraham, K.A. (2003) Familial Cardiac Myxoma: Carney's Complex. Texas Heart Institute Journal, $30,80-82$.

[11] Goswami, K.C., Shrivastava, S., Bahl, V.K., Saxena, A., Manchanda, S.C. and Wasir, H.S. (1998) Cardiac Myxomas: Clinical and Echocardiographic Profile. International Journal of Cardiology, 63, 251-259. https://doi.org/10.1016/S0167-5273(97)00316-1

[12] Cavero, M.A., Cristobal, C., Gonzalez, M., Gallego, J.C., Oteo, J.F. and Artaza, M. (1998) Fatal Pulmonary Embolization of a Right Atrial Mass during Transesophageal Echocardiography. Journal of the American Society of Echocardiography, 11, 397-398. https://doi.org/10.1016/S0894-7317(98)70110-5 
[13] Jones, D.R., Warden, H.E., Murray, G.F., et al. (1995) Biatrial Approach to Cardiac Myxomas: A 30-Year Clinical Experience. The Annals of Thoracic Surgery, 59, 851-855. https://doi.org/10.1016/0003-4975(95)00064-R

[14] Shinfeld, A., Katsumata, T. and Westaby, S. (1998) Recurrent Cardiac Myxoma: Seeding or Multi Focal Disease? The Annals of Thoracic Surgery, 66, 285-288.

https://doi.org/10.1016/S0003-4975(98)00481-0 